\title{
As Leis Agrárias do início da República romana (486-442 a.C.): Conflito pela terra e pelo poder na construção da República romana
}

\section{Agrarian Laws in early Roman Republic (486-442 BC): Conflicts on land and power in the making of Roman Republic}

\section{Las Leyes Agrarias del inicio de la República Romana (486-442 a.C.): Conflicto por la tierra y el poder en la construcción de la República} Romana

\section{José Ernesto Moura Knust}

zeknust@gmail.com

Instituto Federal Fluminense. Universidade Federal

Fluminense, Brasil

Recepção: 01 Fevereiro 2020

Aprovação: 27 Maio 2020

Publicação: 01 Março 2021

Cita sugerida: Knust, J. E. M. (2021). As Leis Agrárias do início da República romana (486-442 a.C.): Conflito pela terra e pelo poder na construção da República romana. Sociedades Precapitalistas, 11, e057. https://doi.org/10.24215/22505121e057
Resumo: Os textos antigos mencionam uma série de propostas de leis agrárias ao longo da história da República romana. Estes textos enquadram estas propostas a partir dos temas ensejados pela crise dos irmãos Graco e pelo enredo do Conflito das Ordens, entre Patrícios e Plebeus. As informações sobre os projetos de lei agrária anteriores aos Graco presentes nos textos antigos são, portanto, em muito contaminadas pelo que seus autores pensavam do episódio gracano. Tendo esse problema metodológico em mente, este artigo apresenta uma reinterpretação sobre o mais antigo ciclo de propostas de leis agrárias que temos notícia, entre 486 e 442 a.C.. A partir do estudo dessas leis, se analisará a questão agrária da época, relacionando-a com as transformações do sistema agrário que a agricultura mediterrânica vivia naquele tempo e com as transformações na posição política do campesinato no contexto da emergência das cidades-estado mediterrânicas.

Palavras-chave: Leis Agrárias, Espúrio Cássio, Início da República Romana.

Abstract: Ancient texts list several proposals for agrarian laws throughout Roman Republic history. The gracchan crisis and the Conflict of Orders between Patricians and Plebeians are the frames used by these texts to explain those proposals. Thus, the information about the pre-gracchan agrarian laws is heavily polluted by the writers' assumptions about the gracchan episode. Tackling this methodological issue, this article presents a reinterpretation of the oldest agrarian law proposals that we know (from 486 to 442 BC). Those laws are explained in the context of the agrarian change in Mediterranean agriculture and the political power of the peasantry in the emergence of Mediterranean citystates.

Keywords: Agrarian Laws, Spurius Cassius, Early Roman Republic. 
Resumen: Los textos antiguos mencionan una serie de propuestas de leyes agrarias a través de la historia de la República Romana. Estos textos cuentan la historia de estas propuestas a partir de los temas propiciados por la crisis de los hermanos Graco y como parte de la trama del conflicto patricio-plebeyo. La información sobre los proyectos de ley agrarios que precedieron a los Gracos en los textos antiguos está, por tanto, muy contaminada por lo que pensaban sus autores sobre el episodio gracano. Teniendo en cuenta este problema metodológico, este artículo presenta una reinterpretación del ciclo más antiguo de propuestas de leyes agrarias que tenemos noticias, entre el 486 y el 442 a.C.. Estas leyes se explicarán como parte del contexto de los cambios en el sistema agrario que estaba experimentando la agricultura mediterránea en ese momento y de los cambios en la posición política del campesinado en el contexto del surgimiento de las ciudades-estado mediterráneas.

Palabras clave: Leyes Agrarias, Cassio Espurio, Inicio de la República Romana.

$\mathrm{A}^{1}$ "questão agrária romana" é um tema clássico dos estudos sobre história econômica e social romana e é o episódio dos irmãos Graco, em finais do século II a.C., que monopoliza boa parte da atenção dispensada ao tema. A tentativa gracana de limitar a ocupação do ager publicus por grandes propriedades e redistribuí-lo em parcelas menores entre as famílias camponesas romanas enseja um violento conflito que para muitos marca o início da crise institucional republicana que só se dissolverá com a ascensão do principado de Augusto. Explicar o contexto econômico e social em que a proposta gracana aparece seria, portanto, uma chave fundamental para entender o século final da República romana, e uma rica bibliografia se construiu em torno do tema (Di Giuseppe, 2005; Frederiksen, 1970; Hopkins, 1978; Launaro, 2011; Ligt, 2012; Patterson et al., 2004; Potter, 1979; Roselaar, 2010; Scheidel, 2004; Toynbee, 1965; Vallat, 1987).

A proposição de leis agrárias não era, contudo, uma novidade trazida pela política gracana. Notícias sobre diferentes leis agrárias estabelecidas ao longo da história republicana abundam nos textos da tradição clássica. Os próprios Tibério e Caio Graco são apresentados nesses textos antigos como políticos que buscavam revitalizar essa tradição de leis agrárias, não como seus inventores. A mais antiga lei agrária mencionada pelos textos antigos data de 486 a.C. - e ela não é relatada como caso isolado. O período entre 486 e 442 a.C., ainda segundo estes textos, testemunha nada menos que outras 38 propostas de algum tipo de lei tratando deste tema (Meunier, 2013, p. 304-307). Se o contexto das leis gracanas é uma chave para entender o último século da república, entender estas leis pode ser uma boa chave para entender o primeiro século da república? Argumento neste artigo que sim.

O estudo destas leis, contudo, enfrenta grandes desafios metodológicos. O grande interesse pela crise gracana não é uma invenção da historiografia moderna - ela também cativou em muito a atenção dos escritores antigos. Como consequência disso, as informações sobre todas as outras leis agrárias que 
aparecem nos textos antigos são de alguma maneira enviesadas pelas questões postas pela crise gracana. Isto é, basicamente tudo que sabemos sobre as leis agrárias anteriores aos irmãos Graco nos é contado, direta ou indiretamente, tendo a questão gracana como subtexto. As informações sobre leis agrárias prégracanas legadas pela tradição clássica são tratadas, portanto, com muita cautela pelos historiadores modernos.

Os escritores antigos muitas vezes recriam os contextos históricos dessas leis utilizando-se de estruturas narrativas modeladas pelo que eles sabiam da história dos irmãos Graco. Motivações, consequências e conteúdos dessas leis são sistematicamente apresentados pelos autores antigos como reencenações do caso gracano, mas tendo o conflito entre patrícios e plebeus como pano de fundo. Tendo a crise dos Graco como modelo, a questão agrária é elevada a uma posição de destaque nessas narrativas para dar conteúdo a este conflito. Diante disso, todo um campo cético quanto as possibilidades de estudar essas leis se estabeleceu na historiografia: mesmo que cada uma delas fossem realmente um fato histórico e não uma invenção literária, o que já seria uma primeira questão, ainda assim tudo que poderíamos saber sobre elas estaria irremediavelmente contaminado pela miopia gracana de nossas fontes.

Outros autores acreditam, porém, que este ceticismo é exageradamente pessimista. Não se nega, isso é importante dizer, que esta questão seja um problema metodológico central para o estudo do tema. Porém, esses autores mais otimistas acreditam ser possível identificar a realidade histórica dessas leis a partir de alguns detalhes e meandros das informações que temos sobre elas - e a partir disso propor algumas hipóteses bem informadas sobre seu conteúdo e contexto histórico. Este método de abordagem demanda que se estabeleçam propostas de interpretação dos dados que temos sobre este período tendo muita clareza sobre três pontos-chave: i) os vieses impostos pela natureza tardia da maioria das nossas fontes; ii) o caráter eminentemente hipotético de quase tudo que se diz de mais específico sobre os acontecimentos históricos da época; iii) as sérias limitações do que é possível conhecer sobre esse período. Este texto tratará especificamente das leis agrárias do período entre 486 e 442 a.C. e se filia a esta segunda perspectiva.

Buscarei compreender o que foram essas diferentes leis agrárias e o contexto em que elas foram estabelecidas. Iniciarei meu argumento tratando especificamente do que a tradição antiga identificava como a primeira proposta de lei agrária em Roma. Temos uma tradição textual prolixa sobre esse evento, a partir da qual pretendo apresentar uma nova interpretação do que teria sido essa lei. Em seguida, analisarei o conjunto das leis agrárias do período, tentando identificar linhas gerais de interpretação possíveis a partir das informações que temos. Por fim, apresento uma proposta de caracterização da questão agrária e de sua relação com o contexto político e as transformações econômicas da época, que explicariam o aparecimento desses projetos de leis agrárias. Pretendo aqui ler estes episódios a contrapelo das estruturas narrativas impostas pelas nossas fontes, que as enquadram fundamentalmente no cenário do conflito entre patrícios e plebeus que acreditavam ter dominado a história dos primeiros séculos da República. Argumento ao longo deste artigo que, apesar de este conflito ter papel importante, ele precisa ser entendido de maneira diferente daquela que nossas fontes o entendiam e que ele não é o único enquadramento histórico que explica a produção dessas leis agrárias. 


\section{Espúrio Cássio e a "primeira lei agrária” (486 a.C.)}

Espúrio Cássio Viscelino foi uma proeminente figura dos primeiros anos da República, cônsul por três vezes $(502,494 \text { e } 486 \text { a.C. })^{2}$. A memória histórica sobre seu nome gira em torno de dois importantes fatos: o acordo orquestrado com os latinos conhecido por foedus cassianum, estabelecido no seu segundo consulado, e o que seria a primeira proposta de lei agrária romana, proposta no seu terceiro consulado. Este segundo fato é narrado pelos textos antigos como parte de um plano de Cássio para tornar-se tirano em Roma, que levaria a sua execução por uma oposição tiranicida.

A tradição romana sobrepôs em um único personagem, portanto, o papel de protagonista do mais importante tratado "diplomático" do início da República e do que seria a primeira proposta de lei agrária romana, além do título de primeiro aspirante à tirania do período republicano. Essa "coincidência", contudo, raramente tem sido levada em consideração nas análises sobre estes episódios. Acredito que uma nova interpretação do que foi a lei agrária de Cássio pode emergir de uma análise que a contextualize junto com este acordo diplomático e a morte de Cássio.

Dionísio de Halicarnasso nos informa que o foedus cassianum estabelecia um acordo de paz e ajuda mútua entre romanos e latinos, estabelecendo regras para divisão de despojos de guerra e para resolução de disputas privadas entre seus cidadãos (Antiguidades Romanas, VI.95). Existe um grande debate em torno do que seriam esses latinos (modernamente chamados de "Liga Latina" pela historiografia) que travam um acordo com Roma. A depender do autor, os latinos e sua "liga" reuniriam as cidades latinas entre as quais Roma (Alföldi, 1965), as cidades latinas lideradas por Roma (Ampolo, 1990, p. 123-126; Forsythe, 2006, p. 187-188) ou as cidades latinas excluindo (mais que isso, se opondo à) Roma (Cornell, 1995, p. 297-298; de Sanctis, 1907).

Uma verdadeira solução para esse debate pode vir, contudo, da superação da ideia arraigada de que são entidades políticas discretas e unitárias, como "Nações", "Cidades-Estado" ou Ligas (os romanos, os latinos) os agentes históricos dessa aliança (Knust, 2019). O foedus cassianum talvez seja melhor entendido como uma rearticulação das classes dominantes da região, reestabelecendo Roma como um local central para essa articulação. Nicola Terrenato propôs que Roma surgiu enquanto cidade-estado como parte de um processo de articulação desses grupos (Terrenato, 2007), e certamente o fim da monarquia em Roma era um momento de tensionamento e renegociação dessa articulação.

Acredito que "Roma" e "Liga Latina" passam a ser dois lócus de articulação alternativos para os diferentes grupos da classe dominante da região neste momento. Depois da ruptura do sistema Tarquínio, a rearticulação se dá de maneira diversa e contenciosa. Um grupo parece reconstruir suas bases de poder tendo a nascente república romana e a cidade de Roma como núcleo central de articulação. Aqui estaria em processo o que Gaetano de Sanctis notoriamente chamou de o "fechamento do patriciado" (de Sanctis, 1907); isto é, a transformação e consolidação paulatina deste grupo social enquanto uma casta governante da Cidade-Estado de Roma. Em resumo, grupos poderosos que tinham se constituído dentro do sistema político Tarquínio, mas que parecem ter rompido com o último rei de Roma, buscam a construção de uma oligarquia 
restritiva em seu centro de poder, Roma, aos poucos dando origem àquilo que conhecemos como o Patriciado romano em sua imagem mais clássica.

Essa é a história bem conhecida dos vencedores, mas é preciso estar atento aos projetos derrotados. Sugiro que, em paralelo a essa construção patrícia, um outro espaço de articulação da classe dominante da região surge no que convencionamos chamar de Liga Latina. Na verdade, mais do que uma Liga estruturada, este sistema seria composto de maneira bem menos institucionalizada e muito mais fragmentada, sendo cada uma das comunidades que fazem parte dele uma espécie de subsistema (Faversani \& Joly, 2015, p. 108) que pode construir articulações diversas entre si, que em seu conjunto constituem um quadro amplo de articulação regional.

A interrupção do expansionismo romano ao longo de boa parte do século $\mathrm{V}$ a.C., normalmente explicada como resultado de um momento de crise e debilidade interna em Roma e de pressão externa de volscos, sabinos e équos (Cornell, 1995, p. 304-309), poderia ser vista, na verdade, como resultado desse novo quadro de articulação dos grupos da classe dominante local. Assim, não é um problema endógeno que freia a expansão romana, porque a expansão romana não é fruto de um processo meramente endógeno. $\mathrm{O}$ foedus cassianum, articulado por Espúrio Cássio após derrotar os latinos em seu primeiro consulado, seria uma tentativa de consolidação deste modelo alternativo de articulação, conectandoo à institucionalidade republicana que se construía em Roma - e que ainda não havia se fechado por completo em torno dos patrícios.

Que papel a lei agrária de Cássio poderia desempenhar neste contexto? Essa lei tradicionalmente tem sido contextualizada diacronicamente em uma enorme lista de propostas de lei presentes nas narrativas históricas que buscavam de alguma maneira distribuir terras entre os plebeus nos primeiros dois séculos da história republicana (Meunier, 2013). Aqui reside um bom exemplo dos perigos da miopia gracana. É muito provável que nossas fontes tenham agrupado um conjunto amplo de medidas distintas em um conceito geral de leis agrárias tendo em mente o contexto do conflito gracano. As poucas leis sobre as quais somos informados em algum nível de detalhe já mostram uma diversidade de objetos e formulações bem sensível, e não parece provável que elas já fossem tomadas em sua época como um conjunto unitário de propostas.

Nicolas Meunier mostra que Tito Lívio, ao tratar dessas leis, se utiliza de um esquema narrativo cíclico que consistem em: 1) as leis agrárias são apresentadas como projetos sediciosos de tribunos da plebe ou de cônsules que agem como se fossem tribunos; 2) o que leva a conflitos entre patrícios e plebeus; 3 ) que é solucionada por uma proposta final, normalmente apresentada por um patrício (com a exceção da Lei Licínia-Séxtia de 367 a.C.), capaz de estabelecer a concórdia entre as ordens (Meunier, 2013, p. 309-322). Isso está claramente determinado pela memória que esses autores tinham da crise dos Gracos: em Tito Lívio, a "lei agrária" é identificada como "o instrumento de sedição privilegiado pelos tribunos da plebe" (Desde a fundação da Cidade, 6.11.8), como a forma dos tribunos de aumentarem seu prestígio (2.42.6) e como o "aguilhão de que se serviam os tribunos para excitar a plebe" (2.54.2). Analisando como o episódio de Espúrio Cássio é retratado especificamente por Dionísio de Halicarnasso, Emílio Gabba é capaz de identificar o quanto toda a narrativa é perpassada por uma 
leitura "gracana" das disputas em torno da "questão agrária" (Gabba, 1964, 1991, p. 186).

Apesar disso, Tim Cornell me parece correto ao afirmar que a invenção historiográfica antiga trabalhou a partir de algum tipo de dado histórico ou de memória histórica de fatos que realmente aconteceram (Cornell, 1995, p. 270). Lendo as narrativas a contrapelo, é possível identificar diversos detalhes informados por Lívio e Dionísio que não se encaixam no modelo narrativo gracano, o que nos serve de indício de que não eram invenções dentro de um topos, mas possivelmente afirmações derivadas de algum tipo de fonte de informações ou tradições históricas. Isto é, se parte substancial da narrativa realmente está determinada pela "forma" do topos gracano, informações que claramente "transbordam" desta forma devem nos chamar especial atenção e servir como trilha metodológica. A partir desse método, algumas coisas podem ser ditas sobre a lei agrária atribuída à Cássio.

Segundo a tradição, esta proposta de lei não incluía apenas os cidadãos romanos entre os beneficiados pelas futuras distribuições de terras. Os latinos, com quem Cássio havia estabelecido o foedus cassianum em seu segundo consulado, assim como os hérnicos com quem Cássio teria assinado um acordo similar no mesmo ano da lei agrária, também receberiam terras (Tito Lívio, Desde a fundação da Cidade, 2.41.1-6; Dionísio de Halicarnasso, Antiguidades Romanas, 8.69.2-4). $\mathrm{Na}$ verdade, Lívio e Dionísio apresentam versões muito distintas sobre como isso se daria. Para o primeiro, o tratado de paz com os hérnicos previa a entrega de dois terços do território destes para os romanos, e a lei agrária previa a distribuição destas terras aos latinos e à plebe (Desde a fundação da Cidade, 2.41.1). Dionísio não menciona cessão de território hérnico aos romanos. Segundo ele, Cássio decidiu distribuir uma grande parcela de ager publicus que havia sido até então negligenciada e ocupada pelos ricos, incluindo entre os beneficiados não apenas a plebe, mas também os latinos e os hérnicos. Portanto, para Dionísio, os hérnicos não só não teriam perdido suas terras como teriam recebido terras públicas romanas, assim como os latinos (Antiguidades Romanas, 8.69.3-4). De toda forma, mesmo para Tito Lívio a posição de Cássio era favorável aos hérnicos, por este devolver terras conquistadas de um povo que até pouco tempo era inimigo (Desde a fundação da Cidade, 2.41.6). Essa é uma informação estranha ao topos gracano e a tudo que sabemos sobre a questão agrária romana - e por isso devemos nos deter nela.

De Sanctis, seguido posteriormente por Cornell, considera que a inclusão de aliados na distribuição de terras públicas romanas seria impossível. Para estes autores, estamos diante de uma clara confusão na tradição entre as disposições dos tratados diplomáticos com esses povos e as disposições de uma lei agrária contemporânea. De Sanctis acredita inclusive que isso deve nos fazer duvidar da existência histórica dessa lei. Ela poderia ser uma invenção posterior, baseada nos termos de distribuição do butim do foedus cassianum, criada para dar à narrativa sobre o primeiro aspirante a tirano da República sua própria lei agrária (de Sanctis, 1907) - e que o único fato histórico concreto nessa tradição seria a tentativa de Cássio de tomar o poder. É uma hipótese bastante plausível.

Cornell concorda que a inclusão dos aliados na distribuição de terras é uma invenção posterior, mas acredita que não é necessário excluir totalmente a possibilidade de que um líder personalista tenha buscado apoio popular 
propondo distribuição de terras para a plebe - mas não para aliados (Cornell, 1995, p. 271). Outra hipótese plausível. Ainda que eu partilhe com esses autores a postura otimista na identificação de fundamentos históricos nessas histórias, gostaria de propor aqui uma terceira interpretação deste episódio em direção exatamente oposta à deles. Para além de apenas alinhavar uma mais uma hipótese que espero que seja também avaliada como plausível, acredito que o exercício interpretativo que proponho a seguir permite concatenar informaçóes sobre o período que normalmente tratamos como desconexas.

O fato de haver uma memória de que Cássio propôs uma lei que distribuía terras aos aliados foge completamente do topos literário gracano e acho que essa é a trilha que precisamos seguir, e não rejeitar, para entender esse episódio. Parece realmente estranho que justamente um dos comandantes que subjugara militarmente essas regiões propusesse uma lei que distribui terras conquistadas entre esses povos subjugados. Isso parece ainda mais paradoxal se aceitarmos a notícia em Dionísio de que Cássio teria proposto a destruição das cidades latinas depois da vitória no Lago Regilo (Dionísio de Halicarnasso, Antiguidades Romanas, 5.20.2). Um mesmo homem subjuga um povo, propõe a destruição de suas cidades e logo em seguida aparece propondo distribuição de terras para esse povo. A justaposição dessas informações no texto antigo gera uma estranheza na narrativa - e é justamente essa estranheza que me parece reforçar que os autores estavam escrevendo sobre elas a partir de informações sólidas sobre os fatos, tendo que adaptar sua narrativa a um cenário que também para eles parecia estranho.

Nicolas Terrenato aponta que, durante os primeiros séculos da República, não é raro perceber uma preocupação recorrente de alguns magistrados romanos com determinadas regiões específicas da Itália - seja para assuntos de guerra ou de paz. Isto é, Cássio não é o único personagem da história romana que tem em uma determinada região tanto o inimigo de uma guerra como o objeto de preocupações "civis" em períodos de paz. Segundo Terrenato, isso mostra a existência de interesses e articulações de uma família ou de um grupo da classe dominante romana naquela região, no que ele chama de interesses privados que conformam a atuação estatal (Terrenato, 2014, p. 51, 2019, p. 155-193).

Espúrio Cássio talvez não fosse exatamente o conquistador de um território inimigo para Roma, mas um articulador de uma região específica para o sistema político centrado em Roma - utilizando ferramentas tão diversas quanto a guerra e as alianças diplomáticas para tanto. Cássio propõe, segundo Dionísio, a destruição das cidades latinas inspirando-se no exemplo de Alba Longa - isto é, com a incorporação da população local à Roma. Essa proposta converge com sua atuação política: A destruição das cidades envolveria uma integração maior das classes dominantes da região no sistema de poder centrado em Roma - dado que eles se mudariam fisicamente para a cidade. Rechaçada essa proposta, Cássio costura uma segunda possibilidade, ofoedus cassianum. Passado algum tempo, ele busca desenvolver essa integração ainda mais, com sua lei agrária.

Minha proposta de interpretação dessa lei, portanto, a retira em um primeiro momento da contextualização diacrônica que a lista no conjunto das leis que buscavam a distribuição de terras para a plebe, do qual as narrativas históricas a fazem ser o episódio inaugural. Proponho contextualizá-la sincronicamente nas guerras e acordos diplomáticos com latinos e hérnicos, que entendo como instrumentos da rearticulação dos grupos da classe dominante regional. 
É impossível conhecermos em detalhe o que a proposta de Cássio previa, mas algumas hipóteses podem ser construídas. $\mathrm{O}$ controle sobre as terras conquistadas constituía a base material do poder da classe dominante. Que a rearticulação política entre estas classes dominantes demande algum tipo de rearticulação sobre o controle da terra, parece bastante provável - e então a lei agrária de Cássio deveria ser um projeto de acordo nesse sentido. Suponho que Lívio e Dionísio, ou suas fontes, tinham essa ponta de informação sobre uma proposta de Cássio sobre reorganização do controle da terra envolvendo latinos e hérnicos e que, enviesados pela narrativa da crise gracana, a tenham entendido como uma lei agrária dentro do modelo gracano de distribuição de terra à plebe.

As guerras lideradas por Cássio contra essas regiões poderiam ser entendidas como enfretamento contra grupos "centrífugos" à Roma ali estabelecidos e é importante perceber que nem todos os grupos da classe dominante nas cidades latinas teriam a intenção de buscar uma articulação com/em Roma. Ao mesmo tempo, contudo, ele tenta integrar as classes dominantes dessa região "centrípetas" à Roma em novas bases, costurando acordos diplomáticos e propondo uma reorganização do controle sobre a terra. É contra este projeto que outra parte da classe dominante romana, aquela que se consolidava dentro do "fechamento do patriciado", se voltou. Este grupo acaba por se sair vitorioso nesse conflito e a via de Cássio para reorganizar o sistema político romano acaba derrotada. Sua derrota custou-lhe a vida e a fama de primeiro aspirante à tirano por toda a história romana. A construção de uma memória de tirano para o derrotado na disputa e de tiranicida para os vitoriosos não deve surpreender.

O que parece insólito, e por isso uma informação preciosa, é que nossas fontes não identificam Cássio como um campeão da plebe. A história de um líder político plebeu propondo uma lei agrária que não recebe apoio entusiasmado da plebe vai diametralmente contra o topos literário gracano. Lívio afirma que a plebe não se interessou em um projeto que beneficiava indistintamente aliados e cidadãos (Desde a fundação da Cidade, 2.41.4). Dionísio apresenta Cássio tentando buscar o poder monárquico através de favores ao povo (Antiguidades Romanas, 8.69.3-4, 8.71.3-4), dentro do topos crítico aos Gracos. Em determinado momento de sua detalhada (e muito provavelmente inventiva) narrativa, contudo, ele se vê obrigado a explicar por que a plebe não teria apoiado Cássio - o que ele atribui à atuação dos tribunos da plebe, que teriam mostrado para a plebe que a distribuição de terras aos aliados proposta por Cássio lhes era prejudicial $(8.71 .5,8.72$.). Ou seja, nossas fontes estão buscando respostas para explicar algo que lhes parecia insólito nas informações históricas que eles tinham.

Parece-me que Lívio e Dionísio lidavam com uma memória de Cássio que claramente o colocava como um articulador de projetos com os "aliados", dos quais seriam parte os tratados com latinos e hérnicos e também a lei agrária, mas sem associá-lo com os cidadãos mais pobres de Roma. A partir disso, conjecturo que Cássio pertença a um grupo com forte presença em Roma, mas que se articula regionalmente de maneira mais próxima às vias do que convencionamos chamar de Liga Latina, opondo-se a outro grupo aristocrático que se articulava em torno do fechamento do patriciado em Roma. Por isso Cássio demonstrava proximidade com os latinos e hérnicos, se preocupava em reorganizar o controle da terra incluindo estes grupos e enfrentava a hostilidade dos patrícios. 
Ainda que a tradição gracana posterior tenha associado Cássio com o movimento plebeu e o tenha tornado um campeão da luta por redistribuição de terras, a população mais pobre de Roma não parece ter sido uma de suas preocupações centrais, sobre o que basta dizer que a primeira Secessão da Plebe ocorre no segundo consulado de Cássio. Segundo o relato de Lívio, os plebeus em secessão teriam cogitado assassinar os cônsules, o que incluiria Cássio - sendo Menênio Agripa, segundo Lívio um plebeu estimado pelo povo, o responsável por apaziguar a revolta plebeia (Tito Lívio, Desde a fundação da Cidade, 2.32). Por isso postulo que Cássio não era um Agripa - isto é, não era alguém com uma proeminência sobre o povo. Cássio, em minha leitura, seria um articulador da classe dominante regional rival dos patrícios. Seu tratado com os latinos e sua proposta de lei agrária seriam, assim, momentos diferentes de uma mesma estratégia, e não mera coincidência histórica.

\section{O primeiro ciclo de projetos de leis agrárias (484-442 a.C.)}

Minha interpretação da lei agrária proposta por Espúrio Cássio precisa enfrentar uma séria questão, porém. Se Cássio realmente não é apresentado pelos textos antigos como campeão da plebe em vida, o tema estabelecido por seu projeto de lei se transforma depois de sua morte em um cavalo de batalha do movimento plebeu nas narrativas de Dionísio e Lívio. Propostas diversas de lei agrária que fazem referência à proposta de Cássio se tornam episódios centrais na história desses autores sobre o conflito entre Patrícios e Plebeus. Não é possível apelar meramente ao ceticismo sobre a realidade histórica dessas propostas que seguem na esteira do projeto de Cássio. Cornell aponta que o debate sobre a terra nesse período narrado pelas nossas fontes tem especificidades em relação à crise gracana que nos permitem rejeitar a ideia de que essas notícias são invenções completas baseadas em uma projeção anacrônica dos problemas gracanos (Cornell, 1995, p. 270). Precisamos explorar o tema, portanto.

Dionísio de Halicarnasso narra que o Senado discutiu sobre o que fazer diante da proposta de Cássio mesmo depois de sua execução (Antiguidades Romanas, 8.74-76.). Duas propostas alternativas à de Cássio aparecem nessa história. Ápio Cláudio afirma que as terras públicas deveriam continuar sendo um bem comum, que beneficiasse a todos e não apenas a alguns cidadãos, como se daria caso elas virassem propriedades privadas. Como solução, ele propõe que os dez ex-cônsules mais velhos formassem uma comissão para dividir a terra pública em parcelas que fossem alugadas em benefício do erário público.

Ainda segundo Dionísio, Aulo Semprônio Atratino faz uma emenda a essa proposta de Cláudio. Além de delimitar essas terras para serem alugadas, parcelas também deveriam ser delimitadas para distribuição entre os plebeus. Mencionase ainda nas deliberações senatoriais que os aliados não teriam direito a parcelas em terras conquistadas apenas pelo esforço romano, mas que a partir do momento da aliança esses povos teriam direito a repartir com os romanos as terras segundo aquilo acordado nos tratados diplomáticos - que estabeleciam uma divisão igualitária do butim de guerra.

O grande problema para a plebe, seguindo a narrativa de Dionísio, é que essa comissão para divisão das terras públicas nunca será criada. Nos anos seguintes, conta Dionísio, tribunos da plebe impediram ou tentaram impedir seguidamente 
o alistamento militar para pressionar que a comissão fosse finalmente criada (Antiguidades Romanas, 8.87.3-5; 8.91.3; 9.1.3; 9.2.2; 9.5.1). Tito Lívio não menciona especificamente essa decisão senatorial de dividir as terras, mas registra os mesmos episódios de tribunos tentando impedir o alistamento a fim de que a "lei agrária" fosse finalmente aprovada (Desde a fundação da Cidade, $2.42 .1 ; 2.42 .6 ; 2.43 ; 2.44 .1)$, o que nos permite pensar que ele tinha informações convergentes com a de Dionísio.

Cinco ou seis anos depois da execução de Cássio, a depender da fonte, até mesmo um cônsul voltaria a defender a repartição de terras entre a plebe. Segundo Tito Lívio, Ceso Fábio teria apoiado a medida em 479 a.C. com o objetivo de conseguir a reconciliação entre as ordens. Dionísio informa alternativamente que Lúcio Emílio, cônsul no ano seguinte, teria defendido a mesma por ódio ao Senado que lhe negara um triunfo (Antiguidades Romanas, 9.17.4-5.). Frente a contínua resistência patrícia em aceitar a repartição de terras, os tribunos aprecem nos anos seguintes processando alguns patrícios para tentar forçar a criação da comissão (Tito Lívio, Desde a fundação da Cidade, 2.52.3, 2.54; 2.61.1.-2; Dionísio de Halicarnasso, Antiguidades Romanas, 9.23.2; 9.25; 9.27.1-5, 9.32; 9.37.1; 9.38.3-4; , 9.51-53).

Apesar das dificuldades metodológicas em analisar essas informações, é possível criar hipóteses acerca da tradição sobre a questão agrária deste período, da qual Dionísio e Lívio fazem uso para criar suas narrativas. Utilizo-me aqui da ideia consolidada por Luigi Capogrossi-Colognesi (1981) de que estamos diante de um momento crítico de conflito entre diferentes formas de propriedade da terra. Isto é, mais do que um debate sobre quantidade e o tamanho das parcelas de terras, a questão em jogo era sobre diferentes formas de se apropriar desse recurso.

A historiadora catalã Rosa Congost, estudando contexto histórico bem diverso, mostra que os direitos de propriedade são formas de proteger determinadas maneiras específicas através das quais determinados grupos sociais se apropriam e controlam o acesso a determinados recursos. Ao mesmo tempo, ainda segundo Congost, essas formas de direito de propriedade, ao reconhecerem estas maneiras específicas como as formas legítimas, desprotegem e deslegitimam outras formas de apropriação e controle de recursos existentes na sociedade. É a dinâmica de conflitos e disputas sociais que determina as formas de apropriação e controle de recursos que são protegidas e as que não são pelos mecanismos do direito de propriedade em uma determinada sociedade. (Congost, 2007, p. 1722). É o acirramento de um conflito deste tipo que vislumbro na primeira metade do século V a.C. na região de Roma.

Uma série de formas distintas de apropriação da terra, que na verdade devem ter se desenvolvido ao longo de décadas, antes e depois de Espúrio Cássio, se encontravam em conflito nas primeiras décadas da República. A transformação do quadro institucional e das articulações sócio-políticas devem ter aberto espaço para o enfrentamento destes distintos projetos, ainda que não possamos descartar a possibilidade de que elas já existiam no período monárquico. A proposta de Cássio de rearticular os latinos e hérnicos dentro desse sistema de propriedade mostraria uma faceta disso; as formas distintas de propriedade que podemos entrever nas disputas posteriores mostrariam outras. Algumas informações presentes nas narrativas históricas, mas às quais os próprios autores 
antigos não parecem dar grande destaque, podem ser o fio da meada para criação de um modelo do que estava acontecendo nesse período.

Um primeiro ponto que me chama atenção nas narrativas de Lívio e Dionísio é que além de tribunos da plebe, que dentro do modelo gracano seriam naturalmente os responsáveis pela agitação da plebe através de leis agrárias, alguns cônsules também são postos neste papel. Meunier mostra que as narrativas históricas encaixam esses cônsules em topos literários recorrentes, como o cônsul frustrado ou que aspira à tirania e por isso se comporta como um tribuno, ou os cônsules responsáveis que tentam pôr fim ao conflito das ordens para trazer harmonia para a cidade (Meunier, 2013, p. 313, 321). Interessa-me, porém, o fato de as narrativas colocarem cônsules nessa situação. Ademais, quando olhamos em detalhe quem são os cônsules envolvidos com as leis agrárias desse período, um aspecto chama atenção: eles se resumem praticamente a membros de duas famílias patrícias específicas, os Fábios e os Emílios. Esse é o tipo de informação que transborda por completo o modelo gracano, e que por isso demanda nossa atenção.

Os Fábios têm nesse período o momento de maior sucesso de uma família nas eleições para as altas magistraturas em toda a história romana: em todos os anos entre 485 e 479 a.C., algum Fábio aparece registrado nos fasti consulares. Gary Forsythe destaca que isso é impressionante não só porque a façanha de eleger sete magistrados principais seguidamente nunca mais será igualada por nenhuma outra família em nenhum outro momento da história romana, mas também porque esse período é aberto pelo primeiro Fábio a ser eleito para um cargo deste nível (Forsythe, 2006, p. 195-196). Isto é, os Fábios ao conseguirem pela primeira vez atingir a mais alta magistratura romana se mantêm lá por um período que nunca mais nenhuma outra família repetirá. Deve-se acrescentar que, entre os colegas de magistratura dos Fábios que os fasti consulares registram para esse período, não há nenhuma família que se repita. Esse período é encerrado pelo famoso e semi-mítico desastre em Cremera que quase leva a gens Fábia à extinção: outro Fábio só aparecerá nos fasti consulares em 467 a.C..

Forsythe destaca que o fato de esse apogeu Fábio se dar exatamente após a execução de Espúrio Cássio deve significar algo. Poderíamos estar diante de uma mudança de grupo aristocrático no poder. Seguindo a lógica da minha análise, derrotado o projeto de articulação com grupos latinos e hérnicos de Espúrio Cássio, outro grupo teria chegado ao poder, liderado pelos Fábios e com outros projetos de articulação de poder.

Esse ser justamente o momento em que as "leis agrárias" emergem como uma questão na história romana me parece ser fundamental. Ao longo dos sete anos de cônsules Fábios temos registros quase anuais de agitações em torno da "lei agrária” (apenas para 482 a.C. não há menção de agitação) e, no ano final desse período, Lívio nos informa diretamente que o cônsul Ceso Fábio era favorável a distribuição de terras para a plebe (Desde a fundação da Cidade, 2.48.2.). No ano seguinte ao massacre em Cremera, o primeiro sem um Fábio como cônsul desde a morte de Espúrio Cássio, Dionísio nos informa que Lúcio Emílio, parceiro de consulado do segundo dos cônsules Fábios, em 484 a.C., apoiou a distribuição de terras em seu segundo consulado (Antiguidades Romanas, 9.17.4-5.).

Em 476 a.C. temos a primeira notícia de uma agitação agrária em um ano em que não há um Fábio ou Emílio ocupando a magistratura principal romana. 
Porém, a agitação em questão é justamente o processo judicial levado a cabo pelos tribunos Quinto Consídio e Tito Genúcio contra Tito Menênio, cônsul em 477 a.C., por ter sido negligente na batalha de Cremera e não ter ido em socorro dos Fábios (Tito Lívio, Desde a fundação da Cidade, 2.52.3; Dionísio de Halicarnasso, Antiguidades Romanas, 9.23.2; 9.25, 9.27.1-5, 9.32.). Os tribunos aparecem solidários aos Fábios mortos, enquanto aqueles que se opõem à lei agrária (apresentados como todos os patrícios nas narrativas históricas, mas que acredito ser um grupo mais específico) aparecem solidários à Menênio. Devemos sempre estar atentos a essas entrelinhas que não se encaixam no modelo geral da narrativa tradicional sobre o período.

A partir daí temos notícias de outras duas “agitações pela lei agrária” em anos em que um Emílio esteve na magistratura principal: 473 a.C. (Tito Lívio, Desde a fundação da Cidade, 2.54; Dionísio de Halicarnasso, Antiguidades Romanas, 9.37.1; 9.38.3-4; 10.38.4) e 470 a.C. (Tito Lívio, Desde a fundação da Cidade, 2.63.2.). Tito Lívio ainda menciona a organização de uma violenta sedição da plebe para reivindicar a distribuição de terras em 469 a.C., abortada por conta da invasão dos volscos (Desde a fundação da Cidade, 2.63.2) - e nesse ano não há Emílio algum no consulado. Por fim, no ano em que finalmente um Fábio volta a ser cônsul, em 467 a.C., temos mais uma vez a lei agrária na pauta (Tito Lívio, Desde a fundação da Cidade, 3.1.2; Dionísio de Halicarnasso, Antiguidades Romanas, 9.59.1-2).

Nem Lívio, nem Dionísio, nem qualquer outro autor antigo parece ter imaginado qualquer relação entre a ascensão dos Fábios ao poder e a emergência das leis agrárias. Isso não surpreende. A tradição histórica romana acreditava que as "agitações pela lei agrária” do início da República, sobre as quais eles deviam ter algum tipo de notícia, deveriam ser explicadas pelo conflito entre patrícios e plebeus e pela ação sediciosa dos tribunos da plebe. Quando se viam frente a alguma notícia de que um patrício se envolvera nessas disputas defendendo uma lei agrária, o procedimento metodológico dos historiadores antigos era buscar uma razão para explicar o que lhes parecia uma excepcionalidade - para o que recorriam aos topoi do cônsul frustrado, tirano ou contemporizador, como bem mostrou Meunier. Acredito que cabe a nós, historiadores modernos, frente ao questionamento sobre o quanto o conflito patrício-plebeu era realmente a dinâmica central da história romana do início do século $V$ a.C., fazer justamente o contrário: deixar de tratar isso como uma excepcionalidade.

A análise das narrativas de Lívio e Dionísio sobre esses episódios me fazem acreditar que havia uma memória histórica que associava paralelamente (e as vezes diretamente) episódios de agitação plebeia em busca de uma "lei agrária" com as famílias Fábia e Emília na primeira metade do século V a.C.. Ao mesmo tempo, não há qualquer construção de memória de que algum membro dessas famílias tenha se tornado um "campeão da plebe" - os Emílios aparecem no máximo frustrados, e os Fábios sempre aparecem conciliatórios e sensatos. Essa incongruência com o modelo gracano me parece um bom motivo para acreditar que nossas fontes estavam realmente diante de informações sobre leis agrárias deste período - ainda que seja difícil sugerir particularmente o que as informações que eles apresentam sobre cada uma das propostas retinham de substancial do conteúdo histórico das questões agrárias do início do século $\mathrm{V}$ a.C.. 
Sugiro aqui a hipótese de que notícia histórica de fundo dessa memória a que Lívio e Dionísio tiveram acesso era a disputa entre formas diferentes de enquadramento da propriedade da terra ensejada pelos conflitos entre projetos distintos de articulação social e política no contexto de construção da República romana. As narrativas históricas, atraídas magneticamente pelo topos gracano, supuseram que essas informações tratavam de um cenário de reivindicações de distribuição de ager publicus para a plebe, a qual se oporiam os patrícios que ocupavam essas terras. Se abandonamos o Conflito das Ordens como ponto de partida e pensarmos o debate sobre a questão agrária em termos de disputa por formas de apropriação da terra, outros caminhos mais interessantes se abrem.

\section{A questão agrária do início da República}

Luigi Capogrossi-Colognesi destacou brilhantemente que a distribuição de ager publicus para a plebe não é uma mera redistribuição de terras - ou seja, uma transformação quantitativa na propriedade fundiária. O processo engendra uma privatização de terras antes públicas - isto é, uma transformação qualitativa na propriedade fundiária. No caso gracano, isso tem menos implicações: as terras públicas a serem distribuídas estavam sendo apropriadas privadamente pelos grandes proprietários, então o que se tem é realmente uma disputa por redistribuição quantitativa da propriedade da terra. No início da República, porém, a situação é menos clara. Muito possivelmente o conceito de agerpublicus não se manteve o mesmo por séculos, então o que sabemos sobre ele para os séculos finais da República não se aplica automaticamente para o início do período. Capogrossi-Colognesi considera que aquilo que as nossas fontes nomeavam por ager publicus poderia ser uma forma anacronizante de se referir a uma maneira distinta de apropriação da terra. Nesse caso, as leis agrárias do início da República estariam lidando com uma questão qualitativa.

Essa ideia levou Capogrossi-Colognesi a propor que estas leis agrárias tinham como objeto não a mera redistribuição da propriedade da terra, mas uma mudança qualitativa na forma de propriedade da terra (Capogrossi Colognesi, 1981). Trata-se de uma ideia preciosa pois recoloca o problema agrário romano dentro de uma verdadeira história das formas de propriedade da terra. Capogrossi-Colognesi acredita que está ocorrendo neste momento uma transição de padrão fundiário. Um sistema baseado em propriedade clânica de terra, que ele chama de ager gentilicus, perde espaço para um sistema baseado na propriedade privada familiar, a partir do qual o padrão clássico da propriedade privada romana se desenvolveria. As bases empíricas para se falar em ager gentilicus são, contudo, muito frágeis (Roselaar, 2010, p. 21-24; Smith, 2006, p. 237-250), e por isso eu gostaria de propor um modelo distinto e menos rigoroso de transição do padrão fundiário.

Em primeiro lugar, acredito que esse processo de transformação foi mais complexo e menos linear. Como Christopher Smith argumenta, nem todos os grupos da classe dominante romana do período deveriam se relacionar com a terra de maneira similar (Smith, 2006, p. 247-250). Uma forma de propriedade próxima ao que se pensa como o ager gentilicus não deve ser descartada como uma das realidades existentes, mas não podemos generalizá-la. Em segundo lugar, se o ponto de partida do processo era complexo, seu ponto de chegada também 
parece ser. Formas distintas de reorganização das formas de propriedade da terra em regióes específicas deviam estar emergindo no período, a depender de diversos fatores. As nossas fontes parecem ter interpretado as notícias que tinham sobre essa diversidade enquadrando-as em três propostas sobre o ager publicus: a divisão da terra com os aliados; o aluguel das terras para gerar recursos para o erário; e divisão de parcelas entre os plebeus.

Não sabemos exatamente o que era entendido como ager publicus nesse momento da história romana. Parece-me bastante razoável, contudo, supor que nossas fontes realmente estavam sendo anacrônicas ao imaginar que essas terras que eram objeto da questão agrária do século $V$ a.C. eram terras de estatuto similar ao ager publicus do período final da República. A partir disso, o mais longe que acho prudente irmos na reinterpretação dessas informações é entender que aquilo que era chamado de ager publicus nas nossas fontes deveria aglutinar algumas formas distintas de propriedade coletiva da terra controlados em níveis diferentes pelos grupos da classe dominante romana. No contexto de reorganização sóciopolítica do início da República, determinados grupos sociais podem ter tentado alavancar algumas dessas formas de propriedade já existentes e/ou algumas outras formas que podem ter emergido deste contexto.

Se não temos informações suficientes para tentar destrinchar mais esse quadro e identificar detalhadamente o processo, algumas hipóteses podem ser aventadas. Grosso modo, as três propostas de tratamento do ager publicus que podemos identificar nas fontes podem ser entendidas como enquadramentos dados por esses autores a notícias sobre tipos específicos de tentativas de estabelecer e proteger novos direitos de propriedade. Essas três formas diferentes de reorganização da propriedade fundiária, por sua vez, podem ser relacionadas a três formas diferentes de rearticulação social e política dos grupos sociais. Ella Hermon identifica o debate sobre a propriedade da terra nesse período entre o Foedus Cassianum e a lei das doze tábuas como um período de desenvolvimento "conceitual" da forma de propriedade da terra. Segundo ela, o conceito de ager publicus é gestado nesse momento através do desenvolvimento de três formas de occupatio: "gentílica", "federal" e viritana (Hermon, 2001, p. 105-110). A precisão dada por Hermon a essas categorias torna sua proposta ainda mais específica que a de Capogrossi-Colognesi, e, portanto, mais especulativa. Para evitar ir tão longe, proporei, aqui, ideias mais gerais sobre essas formas de propriedade.

A preocupação com a divisão das terras com os latinos se insere no quadro $\mathrm{da}$ rearticulação horizontal dos diferentes grupos da classe dominante - e o episódio de Espúrio Cássio é o caso exemplar. Não sabemos exatamente como seria a(s) forma(s) de controle dessas terras, mas a preocupação aqui está em dar acesso aos grupos da classe dominante estabelecidas nas comunidades latinas a esta(s) forma(s). As duas outras propostas podem estar relacionadas a formas diferentes de rearticulação vertical desses grupos da classe dominante com a base camponesa da sociedade, tanto seus clientes e dependentes, quanto os camponeses autônomos - que ao fim e ao cabo, não deviam formar dois grupos sociais completamente distintos entre si. O que as fontes tratam como distribuição de terras pode ter sido, em alguns casos, o reconhecimento da propriedade da terra por parte de famílias camponesas que já a apropriavam na forma de parcelas familiares, mas que tinham que pagar algum tipo de renda a 
senhores de terras patrícios que controlavam a propriedade nominal da terra. $\mathrm{O}$ que as fontes identificam como aluguel de terras públicas seria, na verdade, um conjunto de formas de cobrança dessas rendas.

Algumas considerações mais arriscadas podem ser sugeridas relacionando o que sabemos sobre o quadro político com essas disputas. $\mathrm{O}$ sucesso político dos Fábios na década de 480 a.C. pode estar relacionado justamente por sua articulação com a base camponesa da cidade em novos termos. As notícias que nossas fontes interpretaram como "agitações da plebe pelas leis agrárias" poderiam dar conta de movimentos políticos da base camponesa da sociedade romana em busca de acesso à propriedade da terra com os quais os Fábio poderiam ter se articulado. Isso converge com uma das grandes questões sobre o processo de formação e desenvolvimento das Cidades-Estado no Mediterrâneo antigo: a importância política do campesinato.

A tese da Revolução Hoplítica estabelecia que o novo papel crucial exercido pelos camponeses capazes de se armar hoplitas havia criado um ambiente político que seria a base para o surgimento da Cidade-Estado (Snodgrass, 1965). Apesar de esta ser, hoje, uma tese criticada em alguns de seus aspectos mais importantes (Ducrey, 1999, p. 33-41; van Wees, 2000), continua inegável que a atividade militar que o campesinato passa a desempenhar nesse contexto é incontornável para entender o desenvolvimento da Cidade-Estado mediterrânica antiga (Raaflaub, 2003, p. 28-30; Snodgrass, 1993, p. 61).

Para o caso romano, Christopher Smith aponta que, em paralelo à existência de exércitos controlados por chefes clânicos ou condottieri, temos um processo de formação de um exército romano unitário na segunda metade do século VI a.C. A lendária reorganização serviana do exército romano, presente nas narrativas históricas antigas (Tito Lívio, Desde a fundação da cidade, 1.42-43; Dionísio de Halicarnasso, Antiguidades Romanas, 4.16-19), parece ter nisso a sua base histórica. A formação desse exército é essencial para entender toda a história do período. Teria sido esse exército sob controle régio, mais consistente e poderoso dado que baseado em sua comunidade camponesa, o fator que garantiu à Roma um poder militar capaz de sobrepujar seus rivais regionais (Smith, 2006, p. 289290) e aos monarcas tarquínios o poder sócio-político de controlar a CidadeEstado romana. A queda da monarquia certamente teve impactos sobre essa articulação entre facções e grupos da aristocracia e a base camponesa romana. A ascensão dos Fábios na década de 480 a.C. poderia ter relação com uma bemsucedida estratégia de articulação com esta base social, política e militar.

Além desse quadro político, algumas coisas que sabemos sobre a economia agrária e a geografia da vida camponesa no período também podem nos ajudar a entender essas leis. Tanto no caso do lote viritano quanto no caso de uma parcela arrendada, se prevê uma apropriação real da família camponesa de uma parcela específica de terra. Voltando às ideias de Hermon e Capogrossi-Colognesi, aqui está a raiz da origem dos conceitos legais romanos de usus e dominium que vão aparecer na lei das doze tábuas (Hermon, 2001, p. 107). Isto é, constituise uma forma fundiária específica relacionada com a apropriação familiar de uma parcela exclusiva de terra. O desenvolvimento deste tipo de apropriação da terra certamente está ligado a transformações no sistema agrário e nos tipos de cultivo realizados pelo campesinato romano, assim como em suas formas de assentamento. 
Sobre as formas de assentamento, desde os primeiros levantamentos de superfície realizados na região, ainda na década de 50, tem se identificado o início de um processo de ocupação do território por pequenos assentamentos isolados entre os séculos VI e V a.C. (Attema et al., 2010; De Haas, 2011; Patterson et al., 2004; Potter, 1979; Ward-Perkins, 1955). Tradicionalmente, esses assentamentos foram interpretados como pequenas fazendas camponesas, procedimento hoje posto em dúvida (Ghisleni et al., 2011; Vaccaro et al., 2013; Witcher, 2012). De toda forma, esses resultados comprovam o aumento da presença perene dos camponeses no território agrícola - seja em fazendas isoladas que também lhes servia de moradia, seja em estruturas de tipos variados que eram usados para atividades diversas.

Nas últimas décadas, tem se chamado atenção para o fato de que este mesmo processo de ocupação do território pode ser identificado em várias outras regiões da bacia mediterrânica (Alcock, 2012; Terrenato, 2012; van Dommelen \& Gómez Bellard, 2008), o que indica que estamos diante de um processo de transformação em escala mediterrânica (Knust, 2016, p. 317-408). A relação entre sistemas agrários mais intensivos e a grande presença de assentamentos isolados pelo território já foi sugerida há bastante tempo (Garnsey, 1989, p. 94; Halstead, 1987). A transição de sistemas agrários extensivos para sistemas mais intensivos, para os quais temos bons indícios, é uma explicação central para o processo de surgimento deste padrão de assentamento.

O desenvolvimento destas novas práticas agrícolas e deste novo padrão de assentamento pode explicar a demanda do campesinato romano por mudanças nos direitos de propriedade da terra. Terrenato já sugeriu uma relação entre a intensificação do assentamento e essas leis (Terrenato, 2007, p. 17). Acredito que as transformações nas formas de assentamento levaram a formas específicas de apropriação do solo que geraram conflitos e disputas sociais sobre as formas de propriedade da terra. Isto é, essas "leis agrárias" são resultado do conflito pela busca do reconhecimento e proteção legal a formas de apropriação da terra que estão se desenvolvendo.

Em suma, a questão agrária romana da primeira metade do século $\mathrm{V}$ a.C. deve ser compreendida na interseção dos resultados das transformações políticas e agrárias daquele tempo. Novas formas de produção agrícola ensejavam novas formas de apropriação da terra. Novos papéis desempenhados pelos camponeses na esfera militar, lhes garantiam novas formas de articulação com os grupos aristocráticos. $\mathrm{E}$ os conflitos e alianças entre esses grupos aristocráticos demandavam novas formas de organizar o controle sobre a extração de excedentes da base camponesa. Como resultado de tudo isso, emerge na República romana, durante a primeira metade do século $\mathrm{V}$ a.C., um conflituoso processo de redefinição das formas de controle da terra. São notícias sobre esse processo que nossas fontes traduzem em suas narrativas sobre o conflito em torno das leis agrárias do período.

\section{Referências}

Alcock, S. E. (2012). The essential countryside: The Greek World. In: S. E. Alcock \& R. Osborne (Orgs.), Classical archaeology (2o ed). Chichester; Malden: WileyBlackwell. 
Alföldi, A. (1965). Early Rome and the Latins. Ann Arbor: University of Michigan Press.

Ampolo, C. (1990). Roma arcaica ed i latini nem V secolo. In: G. Colonna (Org.), Crise et transformation des sociétés archä̈ques de l'Italie antique au Ve siècle J.-C. Actes de la table ronde de Rome (19-21 novembre 1987). Roma: Ecole Française de Rome.

Attema, P. A. J., Burgers, G.-J. L. M., \& Leusen, M. van. (2010). Regional pathways to complexity: Settlement and land-use dynamics in early Italy from the Bronze Age to the Republican period. Amsterdam: Amsterdam University Press.

Capogrossi Colognesi, L. (1981). La terra in Roma antica: Forme di proprietà e rapporti produttivi. Roma: La Sapienza.

Congost, R. (2007). Tierras, leyes, historia: Estudios sobre "la gran obra de la propiedad". Barcelona: Editorial Critica.

Cornell, T. (1995). The Beginnings of Rome: Italy and Rome from the Bronze Age to the Punic Wars (c.1000-264 BC). London: Routledge.

De Haas, T. (2011). Fields, farms and colonists: Intensive field survey and early Roman colonization in the Pontine region, central Italy. Eelde: Barkhuis.

De Sanctis, G. (1907). Storia dei Romani, vols. I-II: La conquista del primato in Italia. Torino: Fratelli Bocca.

Di Giuseppe, H. (2005). Villae, villullae e fattorie nella Media Valle Del Tevere. In: B. S. Frizell \& A. Klynne (Orgs.), Roman Villas Around the Urbs: Interaction with Landscape and Environment. Proceedings of a Conference at the Swedish Institute in Rome, September 17-18, 2004. Roma: Swedish Institute in Rome.

Ducrey, P. (1999). Guerre et guerriers dans la Gréce antique (2a ed). Paris: Office du livre.

Faversani, F., \& Joly, F. D. (2015). Expansão na Itália: Da Liga Latina ao saque de Roma. In: J. L. Brandão \& F. de Oliveira (Orgs.), História de Roma Antiga. Volume 1: Das origens à morte de César. Coimbra: Imprensa universitária de Coimbra.

Flower, H. I. (2010). Roman Republics. Princeton: Princeton University Press.

Forsythe, G. (2006). A Critical History of Early Rome: From Prehistory to the First Punic War. Berkeley: University of California Press.

Frederiksen, M. (1970). The contribution of Archaeology to the Agrarian Problem in the Gracchan Period. Dialoghi di Archaeologia, VI-V (2-3).

Gabba, E. (1964). Studi su Diogini d'Alicarnasso. III. La proposta di legge agraria di Spurio Cassio. Athenaeum, 42, 29-41.

Gabba, E. (1991). Dionysius and The History of Archaic Rome. Berkeley: University of California Press.

Garnsey, P. (1989). Famine and Food Supply in the Graeco-Roman World: Responses to Risk and Crisis. Cambridge: Cambridge University Press.

Ghisleni, M., et al. (2011). Excavating the Roman Peasant I: Excavations at Pievina (GR). Papers of the British School at Rome, 79, 95-145.

Halstead, P. (1987). Traditional and Ancient Rural Economy in Mediterranean Europe: Plus ça Change? The Journal of Hellenic Studies, 107, 77-87.

Hermon, E. (2001). Habiter et partager les terres avant les Gracques. Roma: École française de Rome.

Hopkins, K. (1978). Conquerors and slaves. Cambridge: Cambridge University Press.

Knust, J. E. M. (2016). Longe dos muros. Uma história econômica e social do assentamento rural na Itália central tirrênica no contexto da conquista romana (séculos V a III a.C.). Niterói: Universidade Federal Fluminense. 
Knust, J. E. M. (2019). Os Pláucios, a emancipação da plebe e a expansão romana: Conectando as histórias interna e externa da República Romana. Esboģos: histórias em contextos globais, 26(42), 234-254.

Launaro, A. (2011). Peasants and slaves: The rural population of Roman Italy (200 BC to AD 100). Cambridge: Cambridge University Press.

Ligt, L. de. (2012). Peasants, Citizens and Soldiers: Studies in the Demographic History of Roman Italy 225 BC-AD 100. Cambridge: Cambridge University Press.

Meunier, N. (2013). Les constructions narratives chez Tite-Live. L'exemple des leges agrariae dans la première décade de l'Ab Urbe condita. Res Antiquae, 10.

Patterson, H., Di Giuseppe, H., \& Witcher, R. (2004). Three South Etrurian 'crises': First results of the Tiber Valley Project. Papers of the British School at Rome, 72, $1-36$.

Potter, T. W. (1979). The changing landscape of South Etruria. London: Elek.

Raaflaub, K. A. (2003). Soldiers, citizens, and the evolution of the early Greek polis. In: L. Mitchell \& P. J. Rhodes (Orgs.), The Development of the Polis in Archaic Greece. London: Taylor \& Francis.

Richardson, J. H. (2008). Ancient Historical Thought and the Development of the Consulship. Latomus, 67 (2), 328-341.

Roselaar, S. T. (2010). Public Land in the Roman Republic: A Social and Economic History of Ager Publicus in Italy, 396-89 BC. Oxford: Oxford University Press.

Scheidel, W. (2004). Human Mobility in Roman Italy, I: The Free Population. The Journal of Roman Studies, 94, 1-26.

Smith. (2006). The Roman Clan: The Gens from Ancient Ideology to Modern Anthropology. Cambridge: Cambridge University Press.

Snodgrass, A. M. (1965). The Hoplite Reform and History. The Journal of Hellenic Studies, 85, 110-122.

Snodgrass, A. M. (1993). The "hoplite reform" revisited. Dialogues d'histoire ancienne, 19(1), 47-61.

Terrenato, N. (2007). The clans and the peasants: Reflections on social structure and change in Hellenistic Central Italy. In: N. Terrenato \& P. A. R. van Dommelen, Articulating local cultures: Power and identity under the expanding Roman Republic. Portsmouth: Journal of Roman Archaeology.

Terrenato, N. (2012). The essential countryside: The Roman world. In: S. E. Alcock \& R. Osborne, Classical Archaeology (2o ed). Chichester; Malden: Wiley-Blackwell.

Terrenato, N. (2014). Private Vis, Public Virtus. Family agendas during the early Roman expansion. In: J. Pelgrom \& T. D. Stek (Orgs.), Roman Republican Colonisation: New perspectives from archaeology and ancient history. Portsmouth: Journal of Roman Archaeology.

Terrenato, N. (2019). The Early Roman Expansion into Italy: Elite Negotiation and Family Agendas. Cambridge: Cambridge University Press.

Toynbee, A. J. (1965). Hannibal's legacy: The Hannibalic War's effects on Roman life. Oxford: Oxford University Press.

Vaccaro, E., et al. (2013). Excavating the Roman peasant II: Excavations at Case Nuove, Cinigiano (GR). Papers of the British School at Rome, 81, 129-179.

Vallat, J.-P. (1987). Les structures agraires de l'Italie républicaine. Annales. Économies, Sociétés, Civilisations, 42(1), 181-218.

van Dommelen, P., \& Gómez Bellard, C. (Orgs.). (2008). Rural landscapes of the Punic world. London: Equinox. 
van Wees, H. (2000). The development of the hoplite phalanx: Iconography and reality in the seventh century. In: H. van Wees (Org.), War and Violence in Ancient Greece. Swansea: Duckworth and the Classical Press of Wales.

Ward-Perkins, J. B. (1955). Notes on Southern Etruria and the Ager Veientanus. Papers of the British School at Rome, 23, 44-72.

Witcher, R. (2012). 'That from a long way off look like farms': The classification of Roman Rural sites. In: P. Attema \& G. Schörner, Comparative issues in the archaeology of the roman rural landscape: Site classification between survey, excavation and historical categories. Portsmouth: Journal of Roman Archaeology.

\section{Notas}

1 Professor de História do Instituto Federal Fluminense, Campus Macaé. Membro do Núcleo Interdisciplinar de Estudos e Pesquisas sobre Marx e o Marxismo da Universidade Federal Fluminense.

2 Utilizarei apenas por razões práticas o termo cônsul, a despeito da disputa em torno da caracterização da magistratura que esses personagens deveriam ter exercido de fato. Muito possivelmente, o que os textos antigos identificam como listas de cônsules deveriam ser o registro de magistraturas principais com nomes e configurações de poder distintas do que sabemos para os períodos posteriores da República. A instituição do decenvirato, em 450 a.C., e a posterior variação entre cônsules e tribunos militares com poderes consulares como magistraturas principais da República romana, ainda que sejam episódios de difícil interpretação, sugerem um quadro institucional bastante complexo. O consulado muito provavelmente se consolidou como magistratura principal no sistema republicano apenas com a lei Licínia-Sêxtia sobre o consulado (Cornell, 1995, p. 226-229; Flower, 2010, p. 47; Richardson, 2008, p. 337). 